\title{
Editorial: Starting the ADTA's Second Half-Century
}

\author{
Christina Devereaux ${ }^{1}$ - David Alan Harris ${ }^{1}$
}

The American Dance Therapy Association (ADTA) turns 50 this year! We launch the start of the association's second half-century with a full and dense issue reflecting a range of topics informing dance and dance/movement therapy (DMT) interventions, theoretical approaches, and unique contributions with a range of populations.

- To begin, Drs. Leon Rodgers and Charné Furcron conducted a quasiexperimental study to explore whether length of participation in an inner city youth dance program helped young people avoid risky behavior and acquire competence in essential life skills.

- The original article that comes next, Kendra J. Seoane's "Parenting the Self with Self-Applied Touch: A DMT Approach to Self-Regulation," proposes a movement-based approach to self-regulation through phases of self-applied touch.

- University of Copenhagen's Dr. Kasper Levin's article is based on a combined ethnographic and phenomenological qualitative study that draws on the experimental and expressive aesthetics of capoeira to advance a rethinking of the role of movement in ADHD behavior.

- Nell G. Roberts' original contribution, "Embodying self: A DMT approach to working with concealable stigmas," defines a DMT approach for working with socially devalued and negatively stereotyped stigmas that can be hidden from others.

Christina Devereaux

ajdt.christina@gmail.com

David Alan Harris

ajdt.david@gmail.com

1 Department of Applied Psychology, Dance/Movement Therapy and Counseling Program, Antioch University New England, 40 Avon St., Keene, NH 03431, USA 
- In this issue's Narrative, Israeli dance/movement therapist, Yael Barkai, discusses the significance of concentrating on women's hair, and its emotional and symbolic importance within DMT.

After these original articles come highlights from the 50th annual ADTA conference held in La Jolla, California: first, an introduction to and a transcription of Marylee Hardenbergh's 2015 Marian Chace lecture; next, the research poster session abstracts; and finally, a report from the International Panel presentations.

Following the conference material is a review by Amber Elizabeth Lynn Gray of Bessel van der Kolk's 2014 book, The body keeps the score: Brain, mind, and body in the healing of trauma. Book Review Editor Jenny Lee's compendium of recent publications of interest to those in the DMT profession, Of Note, closes the issue.

We trust that readers will agree that the American Journal of Dance Therapy (AJDT) continues to function as a leading disseminator of timely research findings in DMT and, in doing so, plays an important role in the creative arts therapies community. This success depends, of course, on a robust DMT community's enriching contributions - from authors submitting work of quality, as well as expert referees dedicatedly participating in the time-consuming peer-review process and thereby helping maintain professional standards of publication. This issue is the first of two to be published within the ADTA's 50th anniversary year, and we believe that AJDT is well positioned to help address the needs of the ADTA community throughout the next 50 years and beyond.

\section{Compliance with Ethical Standards}

Conflict of interest The authors declare that there is no conflict of interest 